\title{
Effect of Betaxolol on Aspartate Aminotransferase Activity in Hypoxic Rat Retina In Vitro
}

\author{
Satoko Endo ${ }^{1}$, Hiroshi Tomita ${ }^{1, *}$, Sei-ichi Ishiguro ${ }^{2}$ and Makoto Tamai ${ }^{1}$ \\ ${ }^{1}$ Department of Ophthalmology, Tohoku University School of Medicine, 1-1 Seiryou-machi, Aoba-ku, Sendai 980-8574, Japan \\ ${ }^{2}$ Department of Biochemistry and Biotechnology, Faculty of Agriculture and Life Science, Hirosaki University, \\ 3 Bunkyo-cho, Hirosaki 036-8224, Japan
}

Received March 19, 2002 Accepted July 15, 2002

\begin{abstract}
We investigated the effect of betaxolol on the decrease of mitochondrial aspartate aminotransferase (mAAT) activity in rat retinas induced by hypoxia in vitro. It is reported that mAAT decreases in ischemic or hypoxic retina and that the decrease is caused by $\mathrm{Ca}^{2+}$-dependent proteases such as calpain. Betaxolol is a compound that has $\beta_{1}$-adrenergic receptor blocking and voltage-dependent calcium channel blocking properties. The rat eye cups were maintained with Locke's solution saturated with $95 \%$ air $-5 \%$ $\mathrm{CO}_{2}$. The eye cups were immersed in glucose-free Locke's solution saturated with $95 \% \mathrm{~N}_{2} / 5 \% \mathrm{CO}_{2}$ (hypoxic solution). Ninety minutes of hypoxia caused a $20 \%$ decrease in mAAT activity. The eye cups incubated with the hypoxic solution containing $1 \mathrm{mM}$ EGTA, $10 \mu \mathrm{M}$ MK- 801 or $100 \mu \mathrm{M}$ betaxolol were protected from the decrease in mAAT activity, so that the residual mAAT activity was $50 \%, 45 \%$ or $40 \%$, respectively, compared to the eye cups incubated in hypoxic solution alone, which had a $100 \%$ decrease in mAAT activity. In addition, co-incubation with EGTA and betaxolol had a greater protective effect against the mAAT decrease than a single application. This additive effect of betaxolol was dose-dependent. These results suggested that betaxolol had a protective effect against the decrease of mAAT caused by hypoxia and indicated that betaxolol might inhibit the $\mathrm{Ca}^{2+}$ release from intracellular $\mathrm{Ca}^{2+}$ stores.
\end{abstract}

Keywords: Aspartate aminotransferase, Hypoxia, Betaxolol, Neuroprotection, Retina

A number of events occur in glaucoma. All events ultimately lead to the death of retinal ganglion cells (1). It is thought that the cell death in glaucoma is due to the inhibition of axonal transport $(2,3)$ and retinal blood circulation (4-6). $\beta$-Adrenergic antagonists are commonly used in the treatment of patients with glaucoma for reducing elevated intraocular pressure.

Recently many investigators are interested in the neuroprotective effect of anti-glaucomatous agents. The primary action of $\beta$-adrenergic antagonists is to inhibit the receptormediated action of noradrenaline or adrenaline. However, some $\beta$-adrenergic antagonists have also been shown to act as calcium channel antagonists $(7-11)$. Betaxolol is a selective $\beta_{1}$-adrenergic blocker, but its neuroprotective action is generally thought to be due to its calcium channel blocking properties $(8,12)$. Betaxolol also blunted the ischemia-induced damages, more precisely $N$-methyl-Daspartate (NMDA) toxicity (13).

*Corresponding author. FAX: +81-22-717-7298

E-mail: h-tomita@oph.med.tohoku.ac.jp
It is widely believed that intracellular calcium ions play a fundamental role in regulating numerous enzyme activities and mediating the effects of hormones and growth factors that control a wide variety of cellular processes such as metabolism, cell differentiation and secretion. Under ischemic conditions, the intracellular calcium level is elevated through voltage-dependent calcium channels and NMDA receptors. A decrease of $\mathrm{Ca}^{2+}$ pumping results from ATP depletion and then the $\mathrm{Ca}^{2+}$ release from intracellular stores $(14-16)$. Most of the previous studies have shown elevated levels of intracellular $\mathrm{Ca}^{2+}$ under ischemic conditions. Loss of $\mathrm{Ca}^{2+}$ homeostasis may activate $\mathrm{Ca}^{2+}$-dependent enzymes such as proteases, phospholipases (17) and endonucleases, leading to mitochondrial damage and cell death, resulting from energy failure.

In a previous study, we reported the change of aspartate aminotransferase (AAT) activity in ischemic and hypoxic rat retinas (18). AAT catalyzes the interconversion of glutamate, which is believed to be an excitatory amino acid neurotransmitter in the retina $(19-21)$, and oxaloacetate with aspartate and $\alpha$-ketoglutarate. AAT has the highest 
activity among the enzymes for glutamate metabolism $(22-27)$. In our previous study (18), $90 \mathrm{~min}$ of ischemia or hypoxia caused a $20 \%$ decrease in mitochondrial AAT (mAAT) activity, whereas cytosolic AAT (cAAT) activity remained unchanged, and we suggested that mAAT activity may be $\mathrm{Ca}^{2+}$-dependent.

In this study, we tested the effect of betaxolol on decrease of AAT activity induced by hypoxic conditions in vitro.

\section{MATERIALS AND METHODS}

\section{Preparation of samples}

All procedures involving rats adhered to the Guiding Principles for the Care and Use of Laboratory Animals approved by The Japanese Pharmacological Society.

Normal RCS ( $\mathrm{rdy}+/ \mathrm{rdy}+$ ) rats (28) weighing 200 - $250 \mathrm{~g}$ were used. After rats were anesthetized with an intramuscular injection of ketamine hydrochloride $(66 \mathrm{mg} / \mathrm{kg})$ and xylazine hydrochloride $(3.3 \mathrm{mg} / \mathrm{kg})$ mixture, eyes were enucleated. We removed the cornea, lens and vitreous, and we obtained the eye cups. The eye cups were incubated at $37^{\circ} \mathrm{C}$ in Locke's solution $\left(157 \mathrm{mM} \mathrm{Na}^{+}, 2.3 \mathrm{mM} \mathrm{Ca}^{2+}\right.$, $164.2 \mathrm{mM} \mathrm{Cl}^{-}, 3.6 \mathrm{mM} \mathrm{HCO}_{3}^{-}, 5 \mathrm{mM}$ HEPES, pH 7.2) and saturated with $95 \%$ air $/ 5 \% \mathrm{CO}_{2}$ for $90 \mathrm{~min}$ as the control condition. We used glucose-free Locke's solution saturated with $95 \% \mathrm{~N}_{2} / 5 \% \mathrm{CO}_{2}$ for $90 \mathrm{~min}$ as the hypoxic condition. Following this incubation, the separated rat retina was homogenized with $500 \mu \mathrm{l}$ of $0.25 \mathrm{M}$ sucrose using a glassTeflon homogenizer. The homogenate was dialyzed with distilled water for $60 \mathrm{~min}$ to remove endogenous disturbing substances. We obtained a mitochondrial fraction by centrifugation at $4,500 \times g$ for $10 \mathrm{~min}$. The pellet was resuspended in $500 \mu \mathrm{l}$ of $0.25 \mathrm{M}$ sucrose and used for the measurement of mAAT activity. The supernatant was centrifuged at $100,000 \times g$ for $60 \mathrm{~min}$ and then the supernatant was used as the soluble fraction.

Effects of EGTA, MK-801, betaxolol on mAAT activity in hypoxic rat retinas

To examine the protective effects of EGTA $\left(O, O^{\prime}\right.$-bis (2-aminoethyl)ethyleneglycol- $N, N, N^{\prime}, N^{\prime}$-tetraacetic acid), MK-801 (noncompetitive NMDA-receptor antagonist; Sigma, St. Louis MO, USA), and betaxolol on mAAT activity, the eye cups were incubated in glucose-free Locke's solution containing 1 mM EGTA, $10 \mu \mathrm{M}$ MK-801 or $100 \mu \mathrm{M}$ betaxolol and saturated with $95 \% \mathrm{~N}_{2} / 5 \% \mathrm{CO}_{2}$ for $90 \mathrm{~min}$. We measured mAAT activity. To investigate the relation between $\mathrm{Ca}^{2+}$ and the effect of betaxolol, we studied the dose-dependency of betaxolol in the hypoxic condition using glucose-free Locke's solution containing 1 mM EGTA.
Assay of aspartate aminotransferase activity

Activity of AAT was assayed according to the modified method of Godfrey et al. (29, 30). Twenty $\mu \mathrm{l}$ (34 $\mu \mathrm{g}$ protein) of samples was added to a $30-\mu 1$ reaction mixture containing $60 \mathrm{mM}$ imidazole buffer, $\mathrm{pH} 7.4,4 \mathrm{mM} \alpha$-ketoglutarate, $0.7 \mathrm{~g} / 1$ bovine serum albumin, $1.4 \mathrm{ml} / 1$ Triton $\mathrm{X}-100$ and $1.4 \mathrm{mg} / \mathrm{l}$ malate dehydrogenase. Each tube was sonicated for $1 \mathrm{~min}$ on the ice, and the reaction was started by adding $10 \mu \mathrm{l}$ of substrate solution containing of $160 \mathrm{mM}$ L-aspartate and $1.44 \mathrm{mM}$ NADH. Samples were incubated at $37^{\circ} \mathrm{C}$ for $2 \mathrm{~min}$, and then the reaction was stopped by adding $40 \mu \mathrm{l}$ of $0.7 \mathrm{M} \mathrm{HCl}$. After $20 \mathrm{~min}$, required to destroy the remaining $\mathrm{NADH}$ in the acid solution, $1 \mathrm{ml}$ indicator solution containing $95 \mathrm{mM}$ Tris- $\mathrm{HCl}$ buffer, pH 8.5, $860 \mathrm{mM}$ ethanol, $2 \mathrm{mM} \beta$-mercaptoethanol and $11.6 \mathrm{mg} / 1$ alcohol dehydrogenase, was added to each sample. The $\mathrm{NAD}^{+}$was converted to NADH in $30 \mathrm{~min}$. The intensity of fluorescence of each sample was measured with a fluorophotometer (excitation: $340 \mathrm{~nm}$; emission: $460 \mathrm{~nm}$ ). Protein concentration was measured by the method of Lowry et al. (31).

\section{RESULTS}

In our previous study, we reported that $90 \mathrm{~min}$ of ischemia caused a $20 \%$ decrease in mAAT activity whereas cAAT activity remained unchanged, and a similar decrease in AAT activity was observed in vitro after $90 \mathrm{~min}$ of hypoxia (18). The protective effects of EGTA, MK-801 and betaxolol on retinal mAAT were examined. The percentage of protection against decreased mAAT activity is shown in Fig. 1 . The decrease in mAAT activity was $50 \%$ prevented by the addition of $1 \mathrm{mM}$ EGTA, $45 \%$ by $10 \mu \mathrm{M}$ MK- 801 , $40 \%$ by $100 \mu \mathrm{M}$ betaxolol, and $70 \%$ prevented by the addition of both $1 \mathrm{mM}$ EGTA and $100 \mu \mathrm{M}$ betaxolol. Betaxolol showed a dose-dependent protective effect under the hypoxic condition when the buffer contained EGTA (Fig. 2, post-hoc Dunnett's test, $P<0.05$ ).

\section{DISCUSSION}

The present results substantiate that betaxolol acts as a neuroprotective agent against retinal hypoxia. Our previous study showed that $90 \mathrm{~min}$ of ischemia or hypoxia caused a $20 \%$ decrease in mAAT activity and that the mAAT degradation under hypoxic conditions was $90 \%$ prevented by the endoplasmic reticulum $\mathrm{Ca}^{2+}$-ATPase inhibitor thapsigargin in $\mathrm{Ca}^{2+}$-free Locke's solution with EGTA. These results indicated that the decreased mAAT activity may be $\mathrm{Ca}^{2+}$ dependent (18). In this study, we observed the decrease of mAAT activity was partially blocked by MK-801. This result indicated that the decrease of mAAT was caused by $\mathrm{Ca}^{2+}$ entry from the extracellular space mediated through 


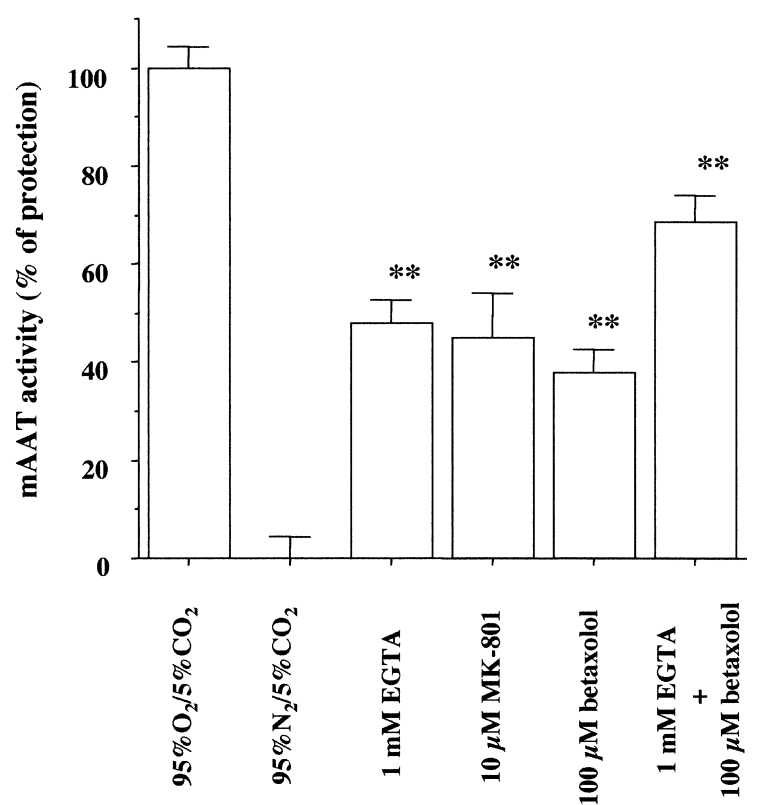

Fig. 1. Effects of EGTA, MK-801 and betaxolol on retinal mAAT activity under hypoxic conditions in vitro. The concentrations of reagent used were $1 \mathrm{mM}$ EGTA, $10 \mu \mathrm{M}$ MK-801, $100 \mu \mathrm{M}$ betaxolol. The reagents were added to Locke's solution saturated with $95 \% \mathrm{~N}_{2}$ $/ 5 \% \mathrm{CO}_{2}$. As a control, the eyecup was incubated in Locke's solution saturated with $95 \% \mathrm{O}_{2} / 5 \% \mathrm{CO}_{2}$ for 90 min. Decreased mAAT activity was $70 \%$ effectively prevented by the addition of $1 \mathrm{mM}$ EGTA and $100 \mu \mathrm{M}$ betaxolol. One hundred percent protection represented no degradation of the enzyme. Each datum point shows the mean \pm S.D. $(\mathrm{n}=4 ; * * P<0.01, t$-test $)$

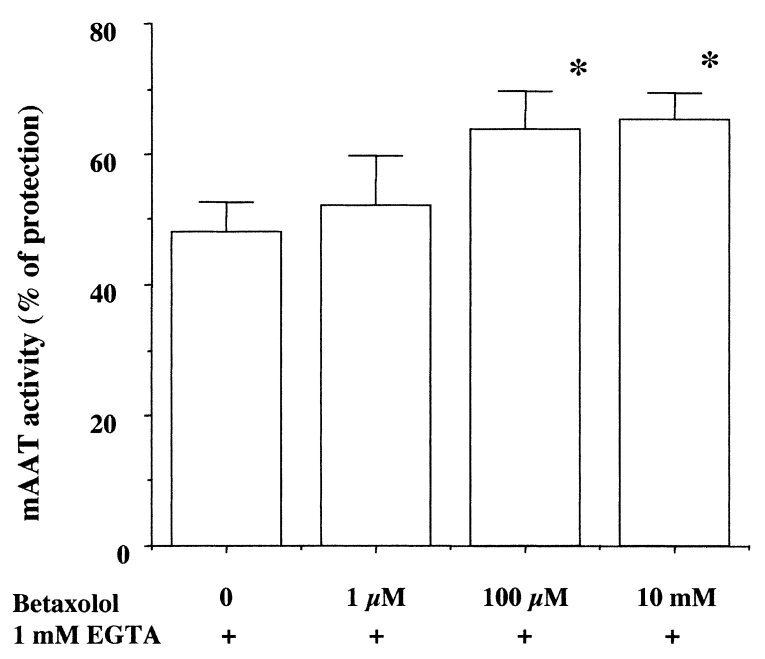

Fig. 2. The effects of betaxolol on retinal mAAT activity under hypoxic conditions in vitro. The concentrations of reagent used were $10^{-8}-10^{-2} \mathrm{M}$ betaxolol. The eye cups were incubated with Locke's solution containing $1 \mathrm{mM}$ EGTA and various concentrations of betaxolol saturated with $95 \% \mathrm{~N}_{2} / 5 \% \mathrm{CO}_{2}$ for $90 \mathrm{~min}$. One hundred percent protection represented no degradation of the enzyme. Each datum point shows the mean \pm S.D. Significant difference vs control group $(\mathrm{n}=4 ; * P<0.05$, post-hoc Dunnett's test for multiple comparisons). Betaxolol had significant dose-dependent protective effects. the NMDA receptor.

Previous reports showed that the AAT activity in retinal layers is predominantly distributed in the outer plexiform layer and photoreceptor inner segments $(32,33)$. Most of the previous studies showed that retinal ischemia thinned the inner retinal layers and reduced the number of cells in those layers, but not in the photoreceptor nuclear layer. However, it should be noted that the photoreceptor segments were shorter and more disorganized than normal (34). Therefore, the photoreceptor cells might be sublethally affected by the cytotoxic processes, and this effect could be due either to the photoreceptors themselves, or to their interacting Müller cells or retinal pigment cells. This suggests that a $20 \%$ decrease in mAAT activity by a 90-min ischemic insult might be induced by the damage of specific cells.

In the present study, the decreased mAAT activity was $50 \%$ prevented by the addition of $1 \mathrm{mM}$ EGTA, $45 \%$ by $10 \mu \mathrm{M}$ MK- $801,40 \%$ by $100 \mu \mathrm{M}$ betaxolol, and $70 \%$ prevented by the addition of both $1 \mathrm{mM}$ EGTA and $100 \mu \mathrm{M}$ betaxolol. Betaxolol is a selective $\beta_{1}$-adrenergic blocker, but its neuroprotective action is generally thought to be due to its calcium channel blocking properties $(8,12)$. We can not exclude the possibility that the selective $\beta_{1}$ adrenergic blocking property of betaxolol is may be related to this neuroprotective effect in this study. However, it is reported that a $\beta$-adrenergic receptor antagonist such as timolol has no neuroprotective effect on NMDA-induced retinal injury (35) and that betaxolol has a greater L-type blocking activity than other $\beta$-adrenergic receptor antagonist (36) and neuroprotective effect on the ischemiainduced retinal injury $(12,13)$. These results suggested that betaxolol may function as a neuroprotective agent by reducing the excessive influx of calcium into the cell in some way (see the Introduction). Under ischemic conditions, the intracellular calcium level is elevated through voltage-dependent and NMDA receptor-operated channels. The ATP depletion causes a decrease of $\mathrm{Ca}^{2+}$ pumping and $\mathrm{Ca}^{2+}$ is released from the intracellular stores $(14-16)$. In our previous study (18), we showed the decrease of mAAT induced by hypoxia was inhibited by co-incubation of EGTA and thapsigargin but not ryanodine. In this study, we observed that betaxolol had an effect similar to that of thapsigargin. These results suggested that betaxolol may reduce the concentration of intracellular calcium ions by preventing calcium ions influx from the extracellular space and by retarding the release of calcium ions from intracellular calcium stores, under hypoxic conditions.

\section{Acknowledgments}

This research was supported in part by Alcon Laboratories, Inc. (Fort Worth, TX, USA) and by a Grant-in-Aid for Scientific Research (No. 13771009) from the Ministry of Education, Culture, Sports, Science and Technology of the Japanese Government. 


\section{REFERENCES}

1 Quigley HA: Ganglion cell death in glaucoma: pathology recapitulates ontogeny. Aust NZ J Ophthalmol 23, 85 - 91 (1995)

2 Radius RL and Anderson DR: Morphology of axonal transport abnormalities in primate eyes. Br J Ophthalmol 65, 767-777 (1981)

3 Quigley HA: Neuronal death in glaucoma. Prog Retin Eye Res 18, $39-57$ (1999)

4 Flammer J and Orgul S: Optic nerve blood-flow abnormalities in glaucoma. Prog Retin Eye Res 17, 267 - 289 (1998)

5 Geijer $\mathrm{C}$ and Bill A: Effects of raised intraocular pressure on retinal, prelaminar, laminar, and retrolaminar optic nerve blood flow in monkeys. Invest Ophthalmol Vis Sci 18, $1030-1042$ (1979)

6 Hayreh SS: Effects of elevated IOP on blood flow. Arch Ophthalmol 101, 1948 - 1950 (1983)

7 Akaike N, Ito H, Nishi K and Oyama Y: Further analysis of inhibitory effects of propranolol and local anaesthetics on the calcium current in Helix neurones. Br J Pharmacol 76, 37-43 (1982)

8 Hester RK, Chen Z, Becker EJ, McLaughlin M and DeSantis L: The direct vascular relaxing action of betaxolol, carteolol and timolol in porcine long posterior ciliary artery. Surv Ophthalmol 38, Suppl, S125 - S134 (1994)

9 Hoste AM and Sys SU: The relaxant action of betaxolol on isolated bovine retinal microarteries. Curr Eye Res 13, 483-487 (1994)

10 Omura T, Kobayashi T, Nishioka K, Miyake N and Akaike N: $\mathrm{Ca}^{2+}$-antagonistic action of bevantolol on hypothalamic neurons in vitro: its comparison with those of other beta-adrenoceptor antagonists, a local anesthetic and a $\mathrm{Ca}^{2+}$-antagonist. Brain Res 706, $289-292$ (1996)

11 Setoguchi M, Ohya Y, Abe I and Fujishima M: Inhibitory action of betaxolol, a beta 1-selective adrenoceptor antagonist, on voltage-dependent calcium channels in guinea-pig artery and vein. Br J Pharmacol 115, 198 - 202 (1995)

12 Osborne NN, Cazevieille C, Carvalho AL, Larsen AK and DeSantis L: In vivo and in vitro experiments show that betaxolol is a retinal neuroprotective agent. Brain Res 751, 113-123 (1997)

13 Osborne NN, DeSantis L, Bae JH, Ugarte M, Wood JP, Nash MS and Chidlow G: Topically applied betaxolol attenuates NMDA-induced toxicity to ganglion cells and the effects of ischaemia to the retina. Exp Eye Res 69, 331 - 342 (1999)

14 Carafoli E: The calcium pumping ATPase of the plasma membrane. Annu Rev Physiol 53, 531 - 547 (1991)

15 Mattson MP, Zhang Y and Bose S: Growth factors prevent mitochondrial dysfunction, loss of calcium homeostasis, and cell injury, but not ATP depletion in hippocampal neurons deprived of glucose. Exp Neurol 121, 1 - 13 (1993)

16 Seubert P, Lee K and Lynch G: Ischemia triggers NMDA receptor-linked cytoskeletal proteolysis in hippocampus. Brain Res 492, 366 - 370 (1989)

17 Nakamura H, Nemenoff RA, Gronich JH and Bonventre JV: Subcellular characteristics of phospholipase A2 activity in the rat kidney. Enhanced cytosolic, mitochondrial, and microsomal phospholipase A2 enzymatic activity after renal ischemia and reperfusion. J Clin Invest 87, 1810 - 1818 (1991)

18 Endo S, Ishiguro S and Tamai M: Possible mechanism for the decrease of mitochondrial aspartate aminotransferase activity in ischemic and hypoxic rat retinas. Biochim Biophys Acta 1450, 385 - 396 (1999)

19 Mayer ML and Westbrook GL: The physiology of excitatory amino acids in the vertebrate central nervous system. Prog Neurobiol 28, 197 - 276 (1987)

20 Rothman SM and Olney JW: Glutamate and the pathophysiology of hypoxic - ischemic brain damage. Ann Neurol 19, $105-$ 111 (1986)

21 Siesjo BK: Mechanisms of ischemic brain damage. Crit Care Med 16, 954 - 963 (1988)

22 Abe T, Ishiguro S and Tamai M: Glutamate dehydrogenase isoenzymes in the bovine retina and human leukocyte. Jpn J Ophthalmol 38, 16 - 23 (1994)

23 Durlu YK, Ishiguro S and Tamai M: Glial markers in iodoacetate retinal degeneration. Prog Clin Biol Res 314, 585-600 (1989)

24 Durlu YK, Ishiguro S, Yoshida A, Mito T, Tsuchiya M and Tamai M: Response of Muller cells following experimental lensectomy-vitrectomy. Graefes Arch Clin Exp Ophthalmol 228, $44-48$ (1990)

25 Ishikawa $\mathrm{A}$, Ishiguro $\mathrm{S}$ and Tamai $\mathrm{M}$ : Changes in GABA metabolism in streptozotocin-induced diabetic rat retinas. Curr Eye Res 15, 63 - 71 (1996)

26 Ishikawa A, Shiono T, Ishiguro S and Tamai M: Postnatal developmental expression of glutamine and related amino acids in the rat retinas. Curr Eye Res 15, 662 - 668 (1996)

27 Shiono T, Hayasaka S and Mizuno K: Development of ornithine ketoacid aminotransferase in rabbit ocular tissues and liver. Invest Ophthalmol Vis Sci 23, 419 - 424 (1982)

28 LaVail MM, Sidman RL and Gerhardt CO: Congenic strains of RCS rats with inherited retinal dystrophy. J Hered 66, 242 - 244 (1975)

29 Godfrey DA, Bowers M, Johnson BA and Ross CD: Aspartate aminotransferase activity in fiber tracts of the rat brain. J Neurochem 42, 1450 - 1456 (1984)

30 Godfrey DA, Ross CD, Parli JA and Carlson L: Aspartate aminotransferase and glutaminase activities in rat olfactory bulb and cochlear nucleus; comparisons with retina and with concentrations of substrate and product amino acids. Neurochem Res 19, 693 - 703 (1994)

31 Lowry OH, Rosebrough NJ, Farr AL and Randall RJ: Protein measurement with the Folin phenol reagent. J Biol Chem 193, $265-275$ (1951)

32 Ross CD, Bowers M and Godfrey DA: Distributions of the activities of aspartate aminotransferase isoenzymes in rat retinal layers. Neurosci Lett 74, $205-210$ (1987)

33 Ross CD and Godfrey DA: Distribution of activities of aspartate aminotransferase isoenzymes and malate dehydrogenase in guinea pig retinal layers. J Histochem Cytochem 35, 669- 674 (1987)

34 Unoki $\mathrm{K}$ and LaVail MM: Protection of the rat retina from ischemic injury by brain-derived neurotrophic factor, ciliary neurotrophic factor, and basic fibroblast growth factor. Invest Ophthalmol Vis Sci 35, $907-915$ (1994)

35 Mizuno K, Koide T, Yoshimura M and Araie M: Neuroprotective effect and intraocular penetration of nipradilol, a betablocker with nitric oxide donative action. Invest Ophthalmol Vis Sci 42, 688 - 694 (2001)

36 Melena J, Stanton D and Osborne NN: Comparative effects of antiglaucoma drugs on voltage-dependent calcium channels. Graefes Arch Clin Exp Ophthalmol 239, 522 - 530 (2001) 